\title{
Para não ser trapo no mundo: as mulheres negras e a cidade na narrativa brasileira contemporânea
} Regina Dalcastagnè ${ }^{1}$

\author{
trapo é corpo expulso do mundo \\ feto expulso do ventre sombra expulsa \\ roupa expulsa sapato jogado fora \\ boné de latão de lixo calça de bueiro
}

Vera Lúcia de Oliveira

Para Marina Farias, Andressa Marques da Silva e Adélia Mathias.

Buscar, nas representações da cidade, aquilo que não se quer ali aqueles que habitam seus desvios, que ameaçam seus muros, os que foram jogados, desde sempre, para o lado de fora. ${ }^{2}$ É preciso um esforço considerável para se encontrar, em meio a uma literatura tão marcadamente de classe média, branca e masculina como a brasileira, uma construção diferente sobre a experiência urbana contemporânea. Carolina Maria de Jesus permanece, assim, como marco fundamental para se ver, e escrever, a cidade para além da "perspectiva do alpendre". ${ }^{3}$ Revisitar sua obra, portanto, é um ponto de partida obrigatório quando se pretende entender as possibilidades poéticas e políticas desse olhar de fora. Neste artigo, busco acompanhar as incursões de mulheres negras e pobres pelo espaço urbano, tentando reconhecer suas estratégias de inserção e sua recusa à qualquer tipo de domesticação. Para isso, serão discutidas narrativas de Carolina Maria de Jesus e de Conceição Evaristo.

Um primeiro problema a ser enfrentado por quem procura essa outra perspectiva é a quase ausência de registros escritos. Gizêlda Melo do Nascimento, autora de Feitio de viver: memórias de descendentes de escravos,

\footnotetext{
${ }^{1}$ Professora titular de Literatura Brasileira da Universidade de Brasília (UnB) e pesquisadora do CNPq, Brasília, DF, Brasil. E-mail: rdal@unb.br

${ }^{2}$ Este texto faz parte das pesquisas "Mulheres e espaço urbano: gênero, raça e classe na literatura brasileira contemporânea" e "Ocupações populares do espaço urbano na narrativa brasileira contemporânea", ambas financiadas com recursos do CNPq.

${ }^{3}$ A expressão é de Roberto Ventura, referindo-se à perspectiva de Gilberto Freyre sobre o canavial: "Com um pé na cozinha e um olhar guloso sobre os prazeres afro-brasileiros, Freyre viu a senzala do ponto de vista da casa-grande, mirou o canavial da perspectiva do alpendre" (Ventura, 2001, [s.p.]).
} 
teve de ir direto à fonte, nas periferias da cidade do Rio de Janeiro, para localizar os narradores da história que se propôs contar. É a partir, especialmente, da fala de velhas mulheres negras que ela consegue instaurar uma narrativa possível sobre aqueles que "encontraram a porta principal da cidade defendida de sua presença" (Nascimento, 2006, p. 5). Sua pesquisa, que retoma o problema da situação dos negros nos espaços urbanos desde suas origens, na Primeira República, pode esclarecer alguns aspectos a serem levantados aqui pela representação literária. Da mesma forma, as narrativas de suas informantes poderiam ajudar a compor um painel mais abrangente e significativo sobre o assunto.

Outra dificuldade, que envolve diretamente autores e autoras, é que, além de serem escassos os documentos sobre os negros e sua relação com a cidade, tampouco a tradição literária está disponível como recurso. Nossa poesia, nossos contos e romances não trazem modelos suficientemente ricos que possam servir de inspiração aos escritores afinal, nunca coube aos negros o papel de protagonistas dessa história. Para recontá-la, "do lado de fora", parece ser necessário ter estado lá. E isso não significa a reivindicação de qualquer ideia de autenticidade. O que está em questão é a perspectiva social de quem fala, ou escreve. De acordo com a definição de Iris Marion Young (2000, p. 136), o conceito de "perspectiva social" reflete o fato de que "pessoas posicionadas diferentemente [na sociedade] possuem experiência, história e conhecimento social diferentes, derivados desta posição". Assim, negros e brancos, mulheres e homens, trabalhadores e patrões, velhos e moços, moradores do campo e da cidade, homossexuais e heterossexuais vão ver e expressar o mundo de maneiras diversas. Mesmo que outros possam ser sensíveis a seus problemas e solidários, nunca viverão as mesmas experiências de vida e, portanto, enxergarão o mundo a partir de uma perspectiva diferente.

Clarice Lispector dá uma mostra clara disso em A paixão segundo G. H. (1964), quando coloca sua protagonista dentro do quarto da exempregada, diante de um desenho feito a carvão na parede: um homem, uma mulher e um cachorro, estáticos, imensos e atoleimados. Como centro do mundo, que imagina ser, a ex-patroa logo supõe que aquelas imagens sejam uma espécie de recado para si:

Olhei o mural onde eu devia estar sendo retratada... Eu, o Homem. E quanto ao cachorro - seria este o epíteto que ela me dava? Havia anos que eu só tinha sido julgada pelos meus pares e 
pelo meu próprio ambiente que eram, em suma, feitos de mim mesma e para mim mesma. Janair era a primeira pessoa realmente exterior de cujo olhar eu tomava consciência (Lispector, 1988[1964], p. 28).

A partir daí, e do esmagamento de uma barata, G. H., a patroa, entra em longas divagações sobre sua própria existência e Janair é soterrada. Dela, só nos sobra a descrição de um desenho na parede, descrição feita pela dona da casa - é bom lembrar -, contaminada pelo rancor e pelas diferenças de classe. ${ }^{4}$

É preciso uma Carolina Maria de Jesus para expressar aquilo que Janair não pode dizer. Tanto em Quarto de despejo (1960) quanto em Diário de Bitita (1982) a autora constrói uma protagonista que não hesita em oferecer sua opinião sobre as patroas (pernósticas, mentirosas, abusivas), nem em lhes dar as costas e ir embora para tratar da própria vida. Suas razões para partir vão desde a revolta contra o preconceito que sente à sua volta até a simples constatação de que está sendo explorada e que não receberá nada pelo seu esforço. Muitas vezes é demitida, por não saber cozinhar, por ser enxerida, por ser relaxada. Também costuma ser acusada de roubos que não cometeu, assim é dispensada antes de receber o que lhe devem. E não havia muito o que fazer, afinal, como dizia sua mãe, "o protesto ainda não estava ao dispor dos pretos" (Jesus, 1986[1982], p. 134). Mas mesmo quando recebe um salário que causa inveja às colegas (Jesus, 1986, p. 200) ela prefere parar de trabalhar para ter tempo para escrever ou para buscar seu sonho da cidade.

Entretanto, bem antes disso, a pequena Bitita tem outro espaço público a conquistar: a escola, que começara a receber os primeiros alunos negros fazia pouco. ${ }^{5}$ Quando entra em uma sala de aula pela primeira vez ela já tropeça nas ofensas dos colegas: "Que negrinha feia!”, “Que olhos grandes, parece sapo” (Jesus, 1986, p. 122). Por isso a menina resiste, falta às aulas, não entende o que a professora lhe pede. Só quando percebe que já consegue ler, o lugar passa a fazer sentido para ela, que, assim, adquire domínio sobre aquilo que antes lhe era estranho. No entanto, essa relação não dura muito - sua mãe precisa se

\footnotetext{
${ }^{4} \mathrm{O}$ espaço das empregadas domésticas em nossa literatura foi analisado anteriormente em Dalcastagnè (2012).

${ }^{5}$ Para uma discussão sobre a educação dos negros no Brasil, ver Gonçalves e Silva (2000).
} 
mudar outra vez para ir trabalhar em uma fazenda, e a escola tem de ser abandonada. A difícil conquista do espaço e sua perda subsequente é tema recorrente nas narrativas da escritora. De qualquer forma, a leitura e a escrita serão para ela, sempre, um lugar seguro. Seu avô, analfabeto que acompanhava com alegria o êxito dos negros, lhe contara um dia que, nas cidades, eles "já sabiam ler e tinham até dinheiro no banco" (Jesus, 1986, p. 81). Portanto, nada mais lógico do que ir para lá.

Em Diário de Bitita - que não é um diário, mas um livro de memórias, no qual, mais uma vez, ela ficcionaliza a si mesma -, Carolina Maria de Jesus conta de sua infância cheia de sonhos, da sua mãe e desse seu avô, o belo e sábio ex-escravo filho de cabindas, de quem ela guarda os conselhos e as histórias. ${ }^{6}$ Resgata madrinhas, tias e vizinhos, alguns simpáticos, mas em sua maioria violentos e racistas. Relembra ainda, junto do avô, a chegada dos imigrantes italianos, mais gentis com os exescravos do que os portugueses que já estavam ali, embora não os explorassem menos. E fala, especialmente, de quando os negros abandonam as lavouras em direção às cidades, levando apenas uma trouxa de roupas e escapando dos fazendeiros, os "ladrões legalizados" da época (Jesus, 1986, p. 140). Seu avô contava da dificuldade de acharem um lugar para si:

Quando eles nos expulsaram das fazendas, nós não tínhamos um teto decente, se encostávamos num canto, aquele local tinha dono e os meirinhos nos enxotavam. Quando alguém nos amparava, nós já sabíamos que aquela alma era brasileira (Jesus, 1986, p. 57).

Nesse livro, bem posterior a Quarto de despejo, a autora registra a história dos seus e dos muitos deslocamentos a que se viram obrigados, do sequestro na África à separação das famílias por conta da venda dos filhos (ou mesmo do casal), passando ainda pela necessidade de se afastar dos ex-proprietários após o final da escravidão, evitando represálias e xingamentos: "Hoje estavam aqui, amanhã ali, como se fossem folhas espalhadas pelo vento. Eles tinham inveja das árvores, que nasciam, cresciam e morriam no mesmo lugar" (Jesus, 1986, p. 58). Mas ela descreve também uma busca própria (que certamente reflete os anseios de muitos outros), a partir de um conselho de sua mãe: “Quem nasce no polo norte, se puder viver melhor no polo sul, então deve viajar para os locais onde a vida seja mais amena" (Jesus, 1986, p. 101).

\footnotetext{
${ }^{6}$ Para uma discussão sobre as relações afetivas das mulheres negras, ver Silva (2013).
} 
Daí o fascínio com a cidade de São Paulo, para onde convergem suas esperanças de, enfim, ser respeitada e poder exercer sua liberdade.

Diário de Bitita termina, depois das muitas andanças de sua protagonista, com o convite para ela ir trabalhar como doméstica na cidade. Empenhada, desde sempre, em entender a movimentação política no país, ela vislumbra São Paulo, logo na chegada, como um espaço progressista, modelo para que "este país se transforme num bom Brasil para os brasileiros" (Jesus, 1986, p. 203). Mostra-se empolgada, inclusive, com o grande número de políticos que a cidade abriga. Com o passar dos anos, sabemos que a autora terá uma nova impressão do lugar e, especialmente, dos políticos, que, segundo seus escritos, só aparecem na favela em época de eleição. De qualquer forma, não deixa de ser interessante notar que Carolina Maria de Jesus, ao fim da vida ${ }^{7}$ e já tão desgastada da cidade com a qual tanto sonhou, tenha escolhido fechar seu livro com a expectativa da chegada em vez de usar a frustração que a acompanhava nos últimos tempos.

Voltando ao Quarto de despejo, podemos reencontrar a protagonista dessa narrativa alguns anos depois de sua chegada em São Paulo, em 15 de julho de 1955, preocupada com o aniversário da filha e com os sapatos que não poderá lhe oferecer. É sintomático o desassossego com os sapatos, que retorna aqui e ali em sua escrita. São eles, afinal, a primeira marca de distinção entre a vida no mundo rural e a do mundo urbano. Não ter sapatos ali, onde os negros deviam saber ler e ter conta nos bancos, podia ser um sinal de seu próprio fracasso. Acompanhamos, então, seu trânsito por São Paulo depois que ela abandona de vez o trabalho como doméstica e passa a viver de pequenas ajudas e da venda de sucata e papel que recolhe nas ruas. É ali que nos deparamos com uma das mais impressionantes expressões do sentimento de exclusão vivenciado por aqueles que ocupam o "lado de fora" da cidade:

Às oito e meia da noite eu já estava na favela, respirando o odor dos excrementos que se mescla com o barro podre. Quando estou na cidade tenho a impressão de que estou na sala de visitas com seus lustres de cristais, seus tapetes de veludo, almofadas de cetim. E quando estou na favela tenho a impressão

\footnotetext{
${ }^{7}$ Carolina Maria de Jesus faleceu em 1977. Pouco antes entregou dois cadernos manuscritos contendo o livro a jornalistas franceses que vieram entrevistá-la. Diário de Bitita foi publicado primeiro na França, pela editora Métailié, e só quatro anos depois saiu no Brasil, pela Nova Fronteira.
} 
de que sou um objeto fora de uso, digno de estar num quarto de despejo (Jesus, 1983[1960], p. 36).

É reveladora a aproximação entre espaço e corpo nesse trecho. O fato de ser obrigada a morar em um lugar feio e sujo faz com que ela se perceba como um trapo descartado. Talvez porque, como diz Pierre Bourdieu, "as imposições mudas dos espaços arquitetônicos se dirigem diretamente ao corpo, obtendo dele a reverência e o respeito que nascem do distanciamento" (Bourdieu, 1993, p. 163). Nos textos de Carolina Maria de Jesus é possível observar tanto o desconforto vivido em espaços hostis quanto a reação de corpos insubmissos, dispostos a ocupar lugares que não lhes são destinados. O confronto corporal é recorrente - como quando ela responde a alguém que reclama de seu cheiro que "quem trabalha como eu tem que feder" (Jesus, 1983, p. 151) ou quando utiliza o preconceito contra a favela a seu favor, ameaçando um homem que a importuna: "Eu sou da favela do Canindé. Sei cortar de gilete e navalha e estou aprendendo a manejar a peixeira" (Jesus, 1983, p. 90). Sua fala funciona como um contraponto ao discurso dominante, que costuma marcar os marginalizados justamente por suas características corporais. Discurso que constrói esses corpos como o "diferente" e, a partir daí, os assinala como "feios, sujos, manchados, impuros, contaminados ou doentes" (Young, 1990, p. 123), forçando-os a lidar, muitas vezes em silêncio, com a aversão ou a condescendência dos grupos privilegiados.

Entre os informantes de Gizêlda Melo de Nascimento surge a lembrança de um pai, negro nascido em torno de 1880, homem maduro, trabalhador e de boa reputação que, nas ruas, "perdia, entretanto, todo o seu equilíbrio quando avistava um policial e corria para se esconder tal qual criança que foge aos castigos dos adultos" (Nascimento, 2006, p. 64). É a imagem de um corpo que vivencia, dolorosamente e contra sua vontade, a "cumplicidade subterrânea [...] com as censuras inerentes às estruturas sociais" (Bourdieu, 1998, p. 45). ${ }^{8}$ Que essa experiência aconteça em meio às ruas da cidade, não é de se estranhar. Marilena Chaui, em texto que discute os problemas da cidadania no Brasil, enfrenta a célebre dicotomia entre casa e rua, de Roberto DaMatta (1997), lembrando que o "mundo da rua" não passa do "mundo da casa" da

\footnotetext{
${ }^{8}$ Bourdieu ressalta que a gagueira, o tremor e o enrubescimento são modos cotidianos de vivenciar corporalmente essa cumplicidade.
} 
classe dominante e que, por isso mesmo, é um espaço tão violento para as camadas populares (Chaui, 1989, p. 135). ${ }^{9}$ Daí os inúmeros relatos em Quarto de despejo e Diário de Bitita sobre as ameaças das autoridades nas ruas - que incluem desde constrangimentos e intimidação, até surras e prisão por desacato ou "perturbação da ordem pública".

A cidade não aparece como um pano de fundo amorfo nas obras de Carolina Maria de Jesus, não é apenas paisagem ou retrato, mas elemento de subjetivação e espaço de empoderamento. Afinal, é ali, transitando de um lado para outro, saindo às ruas para catar suas histórias - seja dentro da favela, seja nas suas cercanias, ou mesmo no centro de São Paulo - que ela se faz escritora. É ali que ela registra, por escrito e com grande alcance, ${ }^{10}$ uma profunda reflexão sobre quem tem o domínio sobre os espaços públicos no Brasil. E, assim, sua escrita se transforma, ela também, em lugar onde experiências se encontram e, de algum modo, se validam. Nesse sentido, é importante sublinhar o impacto da leitura de Quarto de despejo em outras mulheres, negras e pobres como a autora. Conceição Evaristo conta do desejo de escrita que surge em sua mãe, também empregada doméstica, a partir do contato com o texto de Carolina Maria de Jesus:

Nas páginas da outra favelada nós nos encontrávamos. Conhecíamos, como Carolina, a aflição da fome. E daí ela percebeu que podia escrever como a outra, porque ela era também a Outra... São lindos os originais de minha mãe, caderninhos velhos, folhas faltando, exteriorizando a pobreza em que vivíamos. Ali, para além de suas carências, ela se valeu da magia da escrita e tentou, como Carolina, manipular as armas próprias do sujeito alfabetizado (Evaristo, 2011, p. 105).

Escrever, especialmente para aqueles que recém-adquiriram essa capacidade, também pode ser uma maneira de reafirmar sua presença no mundo. Colocar-se em palavras seria, nesse caso, uma forma de ser alguém, de participar de uma coletividade marcada pela escrita e, ao mesmo tempo, ser reconhecido como indivíduo, portanto, único. Quando Conceição Evaristo publica Becos da memória (2006), são pessoas

\footnotetext{
${ }^{9}$ Essa discussão foi trazida por Gizêlda Melo de Nascimento (2006).

${ }^{10}$ Nunca é demais lembrar que Quarto de despejo se tornou conhecido quase imediatamente em mais de quarenta países, foi traduzido para treze línguas e fez de Carolina Maria de Jesus a escritora brasileira mais conhecida no exterior. Cf. Meihy (1998).
} 
como sua mãe que ela pretende resgatar e, de algum modo, inscrever na memória da cidade.

O livro se constitui como um romance sobre uma favela de Belo Horizonte, mais exatamente sobre o fim da favela, ${ }^{11}$ com a expulsão de seus moradores e o desmonte de toda uma rede de afetos que se desdobra nas cercanias da pequena Maria Nova. Os elementos autobiográficos estão distribuídos ao longo da obra, mas o foco é ajustado para olhar a vida ao redor da escritora que está sendo gestada ali, até porque, como diz uma das personagens à menina: "Todos aqueles que morreram sem se realizar, todos os negros escravizados de ontem e os supostamente livres de hoje, libertam-se na vida de cada um de nós que consegue viver, que consegue se realizar" (Evaristo, 2006, p. 103). Ela é, portanto, não apenas testemunha daquilo que relata, mas também depositária da experiência dos seus - e a sua escrita se faz, então, mais uma vez, espaço de luta e de empoderamento.

Muito mais do que no seu romance anterior, Ponciá Vicêncio (2003), em que a protagonista se muda do meio rural para a cidade e depois volta, vencida, para outra vez se fortalecer junto da terra e da mãe, em Becos da memória Evaristo lida com a disputa pela manutenção de um lugar na cidade - afinal, o retorno já não existe como opção. E a favela, diferentemente do que acontece em Quarto de despejo, não é entendida como um lugar à parte, mas como um espaço possível da cidade, um espaço que, ao ser destruído, apaga a história daqueles que viveram e sofreram ali. Sem idealizar a favela, e tampouco as relações estabelecidas em seu interior, a autora captura o momento de dissolução para, a partir daí, constituir suas personagens, entendendo-as em suas sucessivas perdas. Negros e pobres, descendentes de escravos quase todos, com a demolição da favela se tornam, mais uma vez, "folhas espalhadas pelo vento".

Reuni-los nas páginas de um livro é um gesto político que exige alguns ajustes estéticos, até porque essas personagens, como já foi dito, não costumam frequentar nossa literatura como protagonistas. ${ }^{12}$ Talvez por isso mesmo suas histórias não pareçam combinar com a estrutura tradicional do romance, ainda que o romance contemporâneo busque,

\footnotetext{
${ }^{11}$ Cidade de Deus, de Paulo Lins, ao contrário, se inicia justamente com a formação da favela, a partir da chegada dos primeiros moradores, seus objetos, móveis e crenças. Cf. Lins (1997).

12 Para uma discussão mais completa sobre a personagem negra no romance brasileiro contemporâneo, ver Dalcastagnè (2011).
} 
justamente, a variedade de perspectivas e a quebra dos parâmetros estabelecidos. Quando Carolina Maria de Jesus dizia que não entrou no mundo pela sala de visitas, mas pelo quintal (Jesus, 1986, p. 198), ela expunha sua diferença em relação a outras experiências de vida, incluindo aí a dos escritores brancos e de elite, responsáveis quase exclusivos pela perspectiva literária sobre aquilo que nos cerca. Olhar o mundo pela porta de trás pode ser extremamente enriquecedor para nossa literatura, uma vez que o simples deslocamento já pressupõe novas informações, o que exigiria, por sua vez, novos formatos de apresentação.

E. H. Gombrich, discutindo a representação pictórica, lembra que, quando afirmamos que uma imagem se parece com o seu protótipo, queremos dizer que ambas dificilmente seriam distinguíveis lado a lado sob a mesma luz: "Postas sob luzes diferentes, a similaridade desaparece" (Gombrich, 1995, p. 40). Uma vez que o artista não pode transcrever o mundo que vê, mas "apenas traduzi-lo para os termos do meio que utiliza" (Gombrich, 1995, p. 39), é importante entender tanto as suas escolhas quanto a sua perspectiva, além das luzes que incidem sobre elas - o que depende do seu lugar de fala e do nosso local de recepção. Trata-se de um conjunto de fatores relevantes que não são desconhecidos das autoras discutidas aqui. Ao contrário, cientes das implicações trazidas pela sua perspectiva social, elas lidam com isso a seu favor, mobilizando estratégias próprias.

Se Carolina Maria de Jesus trabalhava de modo a salientar a angústia da miséria e da segregação na cidade a partir da repetição - fazendo com que o leitor se sentisse, ele também, enclausurado do lado de fora, sem comida e sem ter para onde ir -, Conceição Evaristo o faz utilizando como recurso a memória afetiva. O leitor não está apenas espreitando vidas alheias em seu romance, ele é convidado a lembrar junto. A fragmentação do discurso acompanha as histórias (de algum modo compartilhadas) que vêm e vão, passando de uma personagem a outra, recompondo-se diante dos olhos interessados de Maria Nova, que funciona como uma espécie de catalisadora das narrativas. Atenta ao mundo ao seu redor, a menina - que fecha os livros para enxergar a vida (Evaristo, 2006, p. 35) - parece saber que é preciso algo mais que a lembrança para que algo permaneça. É preciso o registro dessa existência.

Embora Evaristo inclua muitos homens em seu romance - desde o velho senhor que aguarda a morte, lamentando as perdas vividas, até os garotos que são esmagados em uma brincadeira boba com um trator, 
incluindo ainda o heroico Bondade, amigo de todos e modelo de uma nova masculinidade -, são as mulheres as suas protagonistas. Mulheres de todos os tipos, moças, velhas e meninas, mulheres que amam outras mulheres, que são amadas por homens ou feridas por eles, que estão cansadas de cuidar dos filhos e dos pais, que desistem da vida ou que a celebram. É tamanha a diversidade que a autora pode dispensar os estereótipos, investindo na subjetividade de suas personagens, que são tantas quanto as experiências que incorporam. Mas em todas elas, com diferentes intensidades, está embutido o desejo de pertencimento ao seu espaço - à cidade e à comunidade que estabelecem à sua volta.

É emblemática, nesse sentido, a narrativa sobre Filó Gazogênia, uma das lavadeiras da favela. Após sua morte, durante um bom tempo, sua tina é molhada com a água já usada pelas outras lavadeiras para evitar que rachasse ao sol. Mantêm-se, assim, os laços com aquelas que ficaram - mas o objeto que a representa se desgasta, aos poucos se abre em gretas, perde forma, e acabará por desaparecer também (Evaristo, 2006, p. 149-50). Com o fim da favela, e a dispersão das mulheres que compartilharam com a velha Filó o trabalho diário, os resquícios de sua passagem pelo mundo se apagam - para retornarem, bem mais tarde, como imagem poética na escrita da filha de uma de suas companheiras. O vínculo entre o instrumento de trabalho e a existência da pessoa que o utilizou é muito mais frequente em nossa literatura quando a personagem é masculina. Talvez porque, sendo quase sempre brancas as personagens femininas, raras vezes elas são representadas fazendo trabalhos que exijam força física. ${ }^{13}$ São mulheres, afinal.

Diante da falsa inexorabilidade dessa expressão, cabe retomar aqui as palavras de Soujourner Truth, ex-escrava dos Estados Unidos, que, em um impressionante discurso de 1851, coloca em questão a invisibilidade das mulheres negras no imaginário branco:

Aquele homem diz que as mulheres precisam ser ajudadas a entrar em carruagens, erguidas para passar sobre valas e receber os melhores lugares em todas as partes. Ninguém nunca me ajudou a entrar em carruagens, a passar por cima de poças de lama ou me deu qualquer bom lugar! E eu não sou uma mulher? Olhem pra mim! Olhem pro meu braço! Tenho arado e plantado, e recolhido em celeiros, e nenhum homem poderia me liderar! E não

\footnotetext{
${ }^{13}$ Isso se revela em extensas pesquisas sobre as personagens femininas do romance brasileiro contemporâneo. Ver Dalcastagnè (2010; 2012).
} 
sou uma mulher? Posso trabalhar tanto quanto e comer tanto quanto um homem - quando consigo o que comer - e aguentar o chicote também! E eu não sou uma mulher? Dei à luz treze filhos, e vi a grande maioria ser vendida para a escravidão, e quando eu chorei com minha dor de mãe, ninguém, exceto Jesus, me ouviu! E eu não sou uma mulher? (Truth, 1851).

Ser mulher e ser negra marca um espaço de intersecionalidade onde atuam diferentes modos de discriminação - que ainda é pouco reconhecido. Kimberle W. Crenshaw chama atenção para o problema a partir de um exemplo concreto, no contexto das indústrias norteamericanas:

Na General Motors, os empregos disponíveis aos negros eram basicamente o de postos nas linhas de montagem. Ou seja, funções para homens. E, como ocorre frequentemente, os empregos disponíveis a mulheres eram empregos nos escritórios, em funções como a de secretária. Essas funções não eram consideradas adequadas para mulheres negras (Crenshaw, 2004, p. 10).

A partir daí, as trabalhadoras negras moveram um processo alegando estarem sofrendo discriminação racial e de gênero, mas foram derrotadas.

Também por isso, porque a literatura pode dar a ver situações que são tornadas "invisíveis" e, assim, contribuir minimamente para a sua discussão, é importante que sejam inseridas novas vozes, provenientes de outros espaços sociais, em nosso campo literário. Afinal, são essas vozes autorais que podem, efetivamente, acrescentar substância e originalidade à literatura brasileira. De acordo com Stuart Hall, dentro da cultura, a marginalidade nunca foi um lugar tão produtivo quanto nos dias de hoje, "e isso não é simplesmente uma abertura, dentro dos espaços dominantes, à ocupação dos de fora. É também o resultado de políticas culturais da diferença, de lutas em torno da diferença, da produção de novas identidades e do aparecimento de novos sujeitos no cenário político e cultural" (Hall, 2003, p. 338). Entender as mulheres negras e pobres como parte fundamental desse processo é um passo importante para a democratização de nossa vida cultural e de nossa vida urbana.

\section{Referências}


BOURDIEU, Pierre (1993). Effets de lieu. In: BOURDIEU, Pierre (Org.). La misère du monde. Paris: Seuil.

BOURDIEU, Pierre (1998). La domination masculine. Paris: Seuil.

CHAUI, Marilena (1989). Conformismo e resistência: aspectos da cultura popular no Brasil. 3. ed. São Paulo: Brasiliense.

CRENSHAW, Kimberle W. (2004). A intersecionalidade na discriminação de raça e gênero. In: VV.AA. Cruzamento: raça e gênero. Brasília: Unifem.

DALCASTAGNÈ, Regina (2010). Representações restritas: a mulher no romance brasileiro contemporâneo. In: DALCASTAGNÈ, Regina; LEAL, Virgínia Maria Vasconcelos. Deslocamentos de gênero na narrativa brasileira contemporânea. Vinhedo: Horizonte.

DALCASTAGNÈ, Regina (2011). A personagem negra na literatura brasileira contemporânea. In: DUARTE, Eduardo de Assis; FONSECA, Maria Nazareth (Org.). Literatura e afrodescendência no Brasil: antologia crítica, v. 4 (História, teoria, polêmica). Belo Horizonte: Editora UFMG.

DALCASTAGNÈ, Regina (2012). Literatura brasileira contemporânea: um território contestado. Rio de Janeiro: UERJ; Vinhedo: Horizonte.

DAMATTA, Roberto (1997). A casa e a rua: espaço, cidadania, mulher e morte no Brasil. 5. ed. Rio de Janeiro: Rocco.

EVARISTO, Conceição (2003). Ponciá Vicêncio. Belo Horizonte: Mazza.

EVARISTO, Conceição (2006). Becos da memória. Belo Horizonte: Mazza.

EVARISTO, Conceição (2011). Depoimento. In: DUARTE, Eduardo de Assis; FONSECA, Maria Nazareth Soares (Orgs.). Literatura e afrodescendência no Brasil. v. 4. Belo Horizonte: Editora da UFMG.

GOMBRICH, E. H. (1995). Arte e ilusão: um estudo da psicologia da representação pictórica. Tradução de Raul de Sá Barbosa. São Paulo: Martins Fontes.

GONÇALVES, Luiz Alberto Oliveira; SILVA, Petronilha Beatriz Gonçalves e (2000). Movimento negro e educação. Revista Brasileira de Educação, n. 15, p. 134-158.

HALL, Stuart (2003). Da diáspora: identidades e mediações culturais. Organização de Liv Sovik. Tradução de Adelaine La Guardia Resende et al. Belo Horizonte: Editora da UFMG; Brasília: UNESCO.

JESUS, Carolina Maria de (1986[1982]). Diário de Bitita. Rio de Janeiro: Nova Fronteira.

JESUS, Carolina Maria de (1983[1960]). Quarto de despejo. 10. ed. Rio de Janeiro: Francisco Alves. 
LINS, Paulo (1997). Cidade de Deus. São Paulo: Companhia das Letras.

LISPECTOR, Clarice (1988 [1964]). A paixão segundo G. H. Edição crítica. Paris: Archives; Brasília: CNPq.

MEIHY, José Carlos Sebe Bom (1998). Carolina Maria de Jesus: emblema do silêncio. Revista USP, n. 37, mar./mai., p. 82-91.

NASCIMENTO, Gizêlda Melo do (2006). Feitio de viver: memórias de descendentes de escravos. Londrina: EdUEL.

SILVA, Andressa Marques da (2013). Por uma promessa de vida mais viva: relações afetivas de mulheres negras no rap e no romance brasileiro contemporâneo. Dissertação (Mestrado em Literatura) - Universidade de Brasília, Brasília.

TRUTH, Soujourner (1997 [1851]). Ain't I a woman? In: HALSALL, Paul (ed.). Internet Modern History Sourcebook. New York: Fordham University. Disponível em: <http://www.fordham.edu/halsall/mod/sojtruth-woman.asp >. Acesso em: 2 mar. 2012.

VENTURA, Roberto (2001). Casa-grande e senzala: ensaio ou autobiografia? In: SEMINÁRIO DE TROPICOLOGIA - O BRASIL E O SÉCULO XXI: DESAFIOS E PERSPECTIVAS, 35. Recife, 27 mar. Disponível em: <www.tropicologia.org.br/conferencia/2001casa_grande.html>. Acesso em: 14 out. 2011.

YOUNG, Iris Marion (1990). Justice and the politics of difference. Princeton: Princeton University Press.

YOUNG, Iris Marion (2000). Inclusion and democracy. Oxford: Oxford University Press.

Recebido em maio de 2014.

Aprovado em julho de 2014.

\section{resumo/abstract}

\section{Para não ser trapo no mundo: as mulheres negras e a cidade na literatura brasileira contemporânea}

Regina Dalcastagnè

Este trabalho busca analisar, nas obras de Carolina Maria de Jesus e Conceição Evaristo, as possibilidades estéticas e políticas da autorrepresentação da 
experiência feminina negra nas metrópoles brasileiras. A cidade, nesses livros, não é apenas paisagem ou retrato, mas elemento de subjetivação e espaço de empoderamento, que se efetivam a partir da própria escrita. Fugindo da perspectiva dominante - branca, masculina, elitizada - de nosso cânone literário, Jesus e Evaristo não apenas resgatam "histórias não contadas", como também produzem novos modos de pensar e dizer a relação entre cidade, gênero, raça e classe.

Palavras-chave: cidade, gênero, raça, Carolina Maria de Jesus, Conceição Evaristo.

\section{Not to be rag in the world: Black women and the city in contemporary Brazilian literature}

Regina Dalcastagnè

This paper examines, in the work of Carolina Maria de Jesus and Conceição Evaristo, aesthetic and political possibilities of self-representation of black female experience in Brazilian metropolis. The city, in their books, is not just landscape or portrait, but element of subjectivation and space of empowerment, which become effective from the writing itself. Out of the dominant perspective in our literary canon - white, male, elitist -, Jesus and Evaristo not only rescue 'untold stories' as well as produce new ways of thinking and expressing the relationship between city, gender, race and class.

Keywords: city, gender, race, Carolina Maria de Jesus, Conceição Evaristo. 